\title{
Identification, tracking, validation and forecast of local high resolution precipitation patterns observed through $\mathrm{X}$-band micro radars
}

\author{
Saverio Paolella ${ }^{1}$, Andrea Prato ${ }^{2}$, Stefano Turso ${ }^{1}$, Riccardo Notarpietro ${ }^{1}$, Silvano Bertoldo ${ }^{1}$, \\ Manuela Cucca ${ }^{1}$, Marco Gabella ${ }^{1}$, Giovanni Perona ${ }^{1}$, Silvia Ferrarese ${ }^{2}$, Renzo Richiardone ${ }^{2}$
}

\begin{abstract}
In this paper, the application of a weather radar software for storm identification, tracking and forecast to a short range $\mathrm{X}$-band rain radar observations is presented. Preliminary results are given, applying such tool to high space-time resolution both convective and stratiform precipitation scenarios. Good qualitative and quantitative agreement are observed. Moreover, for the first time, rain derived observations performed by such small radars were compared with independent data. Both high resolution numerical weather forecast models simulations and true observations taken by collocated rain gauges are considered. Good qualitative agreements for both cases are obtained.
\end{abstract}

\section{INTRODUCTION}

Since 2004 with the FORALPS Project ("Meteohydrological Forecast and Observations for improved water Resource management in the ALPS"), the Remote Sensing Group of Politecnico di Torino started to develop a new concept of radar system for high space and time resolution rain monitoring. Such system was based on small, low-cost, low-consuption, unmanned X-band radar devices. The first prototype, running since October 2006, was installed on the Politecnico di Torino roof, sensing both the horizontal and vertical planes. During these years several progresses and modifications were made, leading to a network of micro radars (MicroRadarNet). Actually several micro radars are operative: the ones operated by the Aosta Valley Civil Protection (March 2007) and in an open field in the Klagenfurt Airport (September 2007). Later, a vertical scanner unit was installed next to the glide path of the "S. Pertini" Turin International Airport (June 2010). Latest, four horizontal scanners units were installed in different areas of Sicily (September 2010, see the web site http://meteoradar.polito.it/).

Aim of this paper is twofold: in principle to evaluate the effectiveness of a third party software capable to recognize, track and forecast rain patterns (the Titan software tool). Moreover, for the first time we performed a preliminary validation of the capability of such radar systems to correctly estimate rain intensity. Comparisons were performed against highresolution simulation obtained the Weather Research and Forecasting model (WRF) installed in Environmental Physics Department and against rain gauges data taken from Whether Underground. The latest are supposed to be realistic of effective fallen rain amount comparing radar derived data with independent sources.

\section{THE TITAN TOOL}

The choice of a proper weather monitoring tool for radar applications was an important and crucial step of the entire development activity of MicroRadarNet. A certain number of weather analysis softwares are made and some of them are free available for the community. Among them, the research project called TITAN (i.e Thunderstorm Identification Tracking Analysis and Nowcasting - Dixon and Wiener, 1993) was found to be particularly suitable for our purposes. TITAN was adopted in a number of international weather projects, and this motivated the selection of this weather software. TITAN is a software implementing particular methodologies for identification, tracking and forecasting of storms, based on volumetric weather radar data. A storm is defined as a contiguous region exceeding both volume and reflectivity thresholds. For the cases studied in this paper these thresholds were set at $25 \mathrm{~km}^{2}$ and $10 \mathrm{dBZ}$ (roughly $0.1 \mathrm{~mm} / \mathrm{h}$ ). Once the storm is identified, the tracking algorithm runs to evaluate the most likely storm pattern centroid movement. Given a set of storms at time $t_{1}$ and a set at time $t_{2}$, TITAN tries to solve the matching problem to identify the most likely paths describing the motion of each storm centroid. This is done also taking into account that the number of storms at time $t_{1}$ may differ from the number at time $t_{2}$, caused by storms merging and/or splitting. Some basic assumptions are made: shorter paths are preferred rather than longer ones; similar storms are more likely to join; a maximum storm speed may not be exceeded.

After the storm is identified and tracked, the forecast is attempted. The forecasting algorithm works assuming that a typically storm tends to move along a straight line and storm growth and decay follow a

\footnotetext{
${ }^{1}$ Electronics Dept., Politecnico di Torino, Torino, Italy (nome.cognome@ polito.it)

${ }^{2}$ Dipartimento di Fisica Generale, Università degli Studi di Torino, Torino, Italy (prato@studenti.ph.unito.it; ferrares@ph.unito.it; richiard@ph.unito.it)
} 
linear trend. It is evident that, in order to be able to accomplish these functions, TITAN needs an history of the storms behavior corresponding to some previous maps (in our case radar observations performed during the previous 6 minutes are taken).

\section{THE WRF MODEL SIMULATION}

The Weather Research and Forecasting (WRF) model is a numerical weather prediction (NWP) and atmospheric simulation system designed for both research and operational applications (see http://www.wrf-model.org). The development of this tool has been a multi-agency effort to build a nextgeneration mesoscale (from tents to hundreds $\mathrm{km}$ coverage) forecast model and data assimilation system to improve the understanding and prediction of mesoscale weather. Input data from ECMWF global model have been used to drive WRF simulations. High-resolution WRF (version 3.2) simulations have been launched to evaluate the agreement between forecast and radar observations performed for a certain meteorological event. Since the Micro Radar covers a circular area with a radius of about $30 \mathrm{~km}$, with a range resolution of $120 \mathrm{~m}$ and with an angular resolution of $3^{\circ}$, we choose the finest resolution allowed by WRF that could cover the entire observation area of the radar, i.e. a resolution of $1 \mathrm{~km} \mathrm{x} 1 \mathrm{~km}$, reached through the use of 4 "nested" grids. Starting from a spatial resolution of $27 \mathrm{~km}$ and using a spatial resolution ratio of 3 between two consecutive grids, we got $1 \mathrm{~km}$ resolution for the last and smallest grid centered on radar position with a number of grid points, $88 \times 79$, from West to East and from South to North respectively. As allowed by WRF, some physical processes can be parameterized choosing from different schemes. In this case we used: WSM-6 microphysics scheme, Rapid Radiative Transfer Model longwave radiation scheme, Dudhia shortwave radiation scheme, Noah land surface model, Yonsei University scheme for boundary layer and the KainFritsch scheme for cumulus parameterization. All the Output data from WRF model are contained in georeferenced matrix form. From these, the RAINNC variable on the $4^{\text {th }}$ grid has been selected, corresponding to total accumulated rain from the initial simulation instant. After that, subtracting output values referred to each hour, accumulated rain in 1 hour $(\mathrm{mm})$ has been achieved. Since radar has a range of about $62 \mathrm{~km}$ diameter, the $63 \times 63$ submatrix centered on the radar (corresponding to the minimum WRF square area that could cover the circular radar area) is extracted. In order to perform radar-WRF comparisons and radar-rain gauge comparisons, radar data where averaged in space in order to obtain, for each 1 minute radar map, a similar 63x63 georeferenced matrix with $1 \mathrm{~km} \times 1 \mathrm{~km}$ resolution. In computing the space rain averages, particular attention was paid in removing ground clutter radar pixels (radar intense echoes coming from ground reflections) and outliers. Accumulated hourly rain values are then computed for each of the $63 \times 63$ final map pixel.

\section{RESULTS}

\subsection{TITAN forecasts}

Twenty rainy days from May 2009 to October 2010 recorded by the MicroRadarNet radar placed on the Politecnico roof (in the center of Turin) were analyzed. Before showing a comprehensive statistical study of the entire dataset, we consider a single TITAN's forecast trial as example.

Figure 1 (top-left) shows a graphical representation of a convective event recorded on July 17th, 2009 with respective detection and forecast. Actual storm evolution is then plotted in Figure 1 (top-right) and the previous forecast is superimposed for comparison (light red area). The same graphical representation is proposed in Figure 1 (bottom-left and bottom-right) for the same event but 30 minutes later. It's clear that TITAN is effectively able to predict the storm motion with a reasonable accuracy, both as direction and speed, just less as shape of the storm.

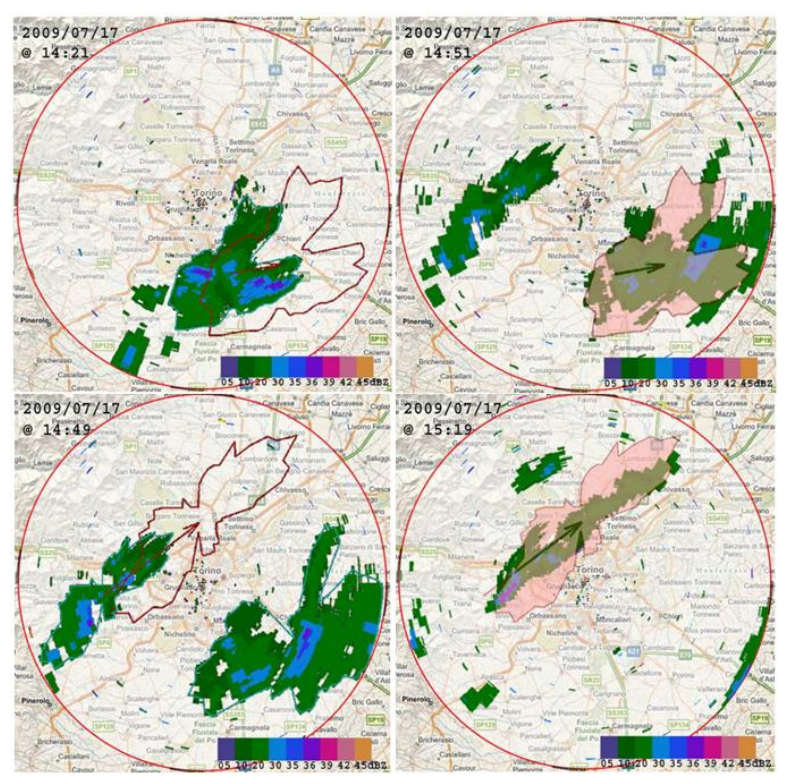

Figure 1: Example of TITAN detection and forecast

In evaluating and testing forecast software it's necessary to know what type of meteorological phenomena (convective or stratiform) we are considering. To better understand the forecast effectiveness to different meteorological events, a statistical evaluation has been performed considering 
the overall observations performed from May 2009 to October 2010. Storm velocity, duration and covered area are firstly analyzed and results are shown. Figures 2 (left) relates storm areas and corresponding duration while figure 2 (right) storm velocity and corresponding covered areas are related, for the convective events taken into account. In this case small storms have generally short duration (less than 2 hours) but high velocity (usually around $20-60$ $\mathrm{km} / \mathrm{h}$ ). Very slow storms are also present, which can lead to an erroneous evaluation of the statistical analysis. This is due to the fact that mostly rainfall events have both convective and stratiform characteristics.

The same evaluations were attempted considering the subset of considered stratiform events. Storm areas versus duration (figure 3 - left) and velocity versus covered areas (figure 3 - right) reflects the different storm behavior. Again, smaller storms with a short duration are sensed, together with larger storms with much longer durations. Velocities are generally smaller, indicating slow centroid movement for most of the detected stratiform storms.

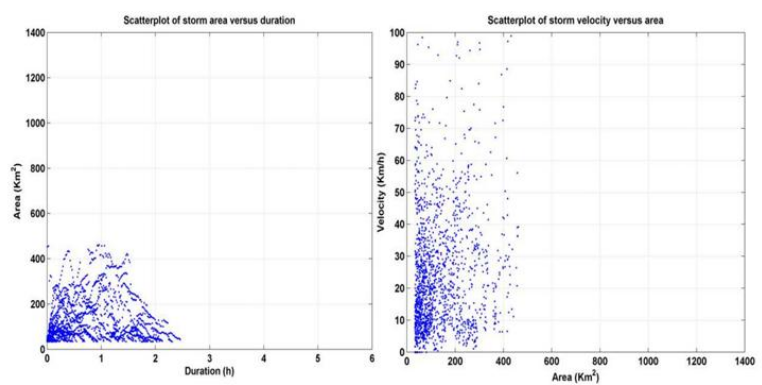

Figure 2: Convective events parameters behavior.

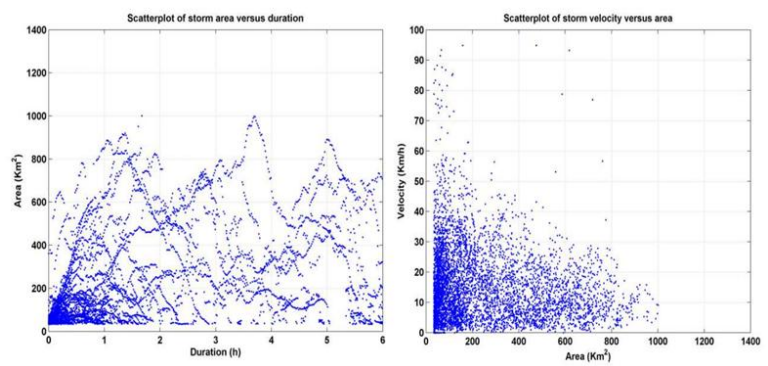

Figure 3: Stratiform events parameters behavior

The estimation of the forecast effectiveness is then performed comparing predicted storm positions with actual ones evaluated at the forecast time. Assuming that a grid point of a map is considered "active" if any radar point in the area around that grid point exceeds the storm reflectivity threshold, the dichotomous (Yes/No) contingency table is evaluated and the following definitions are applied:

- success: forecast (TITAN output) and truth (radar observations) grid points both active
- failure: inactive forecast point and active truth point - false alarm: active forecast point and inactive truth point. The Probability Of Detection (POD), the False Alarm Ratio (FAR) and the Critical Success Index (CSI) can be computed as:

$$
\begin{aligned}
& \text { POD }=\frac{n_{\text {success }}}{\mathbf{a}_{\text {success }}+n_{\text {failure }}-} \\
& \text { FAR }=\frac{n_{\text {falsealarm }}}{n_{\text {success }}+n_{\text {falsealarm }}} \\
& \text { CSI }=\frac{n_{\text {success }}}{n_{\text {success }}+n_{\text {failure }}+n_{\text {falsealarm }}}
\end{aligned}
$$

(Wilks, 1995). Evaluations of the forecasts are shown in Table 1 for both convective and stratiform events. These results are obtained by averaging forecasts evaluations performed on all twenty rainy events available. Of course, it is expected that longer forecast lead time gives smaller probability of detection (POD). An important aspect regarding the ability of TITAN to predict storms motions is the performance difference between convective events and stratiform events. stratiform events, in fact, are more easily predictable because of a slower motion and a simpler evolution of the storms.

\begin{tabular}{|c|ccc|c|c|c|}
\hline \multirow{2}{*}{ Forecast Lead Time } & \multicolumn{3}{|c|}{ Convective events } & \multicolumn{3}{c|}{ Stratiform Events } \\
\cline { 2 - 7 } & POD & FAR & CSI & POD & FAR & CSI \\
\hline 5 & 0.759 & 0.272 & 0.592 & 0.869 & 0.145 & 0.758 \\
\hline 10 & 0.645 & 0.408 & 0.446 & 0.796 & 0.232 & 0.643 \\
\hline 15 & 0.570 & 0.514 & 0.352 & 0.736 & 0.302 & 0.561 \\
\hline 20 & 0.517 & 0.589 & 0.290 & 0.687 & 0.362 & 0.498 \\
\hline 30 & 0.418 & 0.705 & 0.203 & 0.627 & 0.445 & 0.421 \\
\hline
\end{tabular}

Table 1 - Skill scores evaluations

\subsection{Radar - WRF - Rain Gauge comparisons}

The case study analyzed concerns both a stratiform and convective rainfall event occurred in Piedmont (NorthWest Italy) on 20 and 21 November 2010. During the autumn season, precipitation events in our region are normally stratiform. But, in this case, the convection of air masses due to orographic lift over the French side of the Alps and frontal convection over Southern France and Mediterranean sea, which is caused by the warm air masses rising because of cold air masses approach, caused also a convective character.

A simulation of 7 days and 18 hours, from 14 November (00:00 UTC) to 21 November 2010 (18 UTC), has been chosen. The comparison with rain gauges was treated after the recognition of rain gauge points over the georefenced matrix, equal for radar and WRF. Figures 3 and 4 show two examples of qualitative comparison of hourly accumulated rain over rain gauge points located in Castagneto Po (lat $45.161^{\circ}$, lon $7.89^{\circ}$ ) and in Ciriè (lat $45.226^{\circ}$, lon 
$\left.7.60^{\circ}\right)$. The plots show that the general trend is described quite well by all three systems. In particular, a good agreement between rain gauges and radar observations can be noticed, while WRF shows more different fluctuations in temporal trend and forecasts the maximum peak 2-3 hours later with respect to radar and rain gauge. From this quantitative analysis, rain measures show a similar order of magnitude but, in the specific, some differences occur.

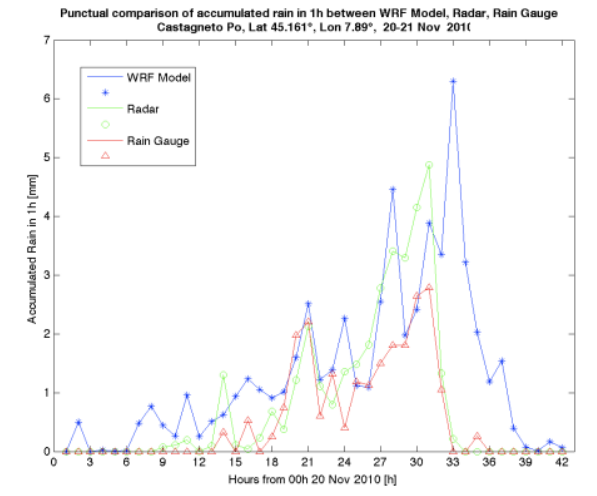

Figure 3: Comparisons over Castagneto Po

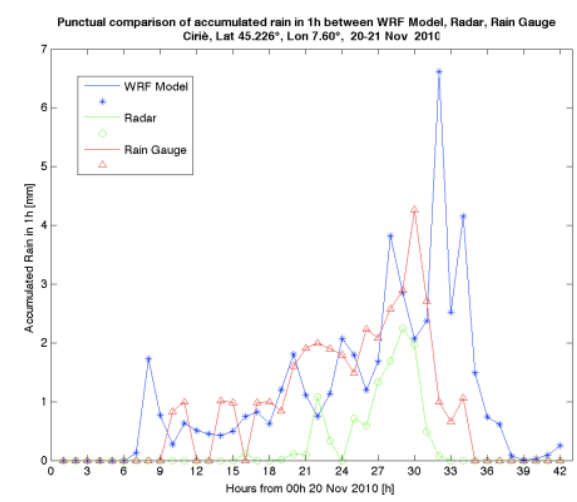

Figure 4: Comparisons over Ciriè

In Castagneto Po total accumulated rain evaluated by WRF, radar and rain gauge is $54.81 \mathrm{~mm}, 33.21 \mathrm{~mm}$ and $22.58 \mathrm{~mm}$ respectively, while in Ciriè is $43.11 \mathrm{~mm}$, $10.89 \mathrm{~mm}$ and $36.89 \mathrm{~mm}$ respectively. WRF simulations overestimate the amount of rain over both points while, radar overestimation and underestimation compared to rain gauges probably depend on partial beam occultation presence over considered points: overestimation occurs in Castagneto located Eastward (radar region less subject to beam occultation), while underestimation occurs over Ciriè, located to North (higher-risk beam occultation area).

The same skill scores (POD, FAR and CSI) of radarrain gauges and radar-WRF comparisons has been evaluated analyzing the corresponding contingency tables. In radar-rain gauge comparison, in addition to the previous rain gauges, those corresponding to Nichelino and Pecetto has been added. For radar-WRF comparison we considered each WRF and radar data couple referred to the same place and the same time and we assigned it to a certain contingency table element according to its categories.

\begin{tabular}{|c|c|c|c|c|c|}
\hline \multicolumn{3}{|c|}{ Radar - Gauge } & \multicolumn{3}{c|}{ Radar - WRF } \\
\hline POD & FAR & CSI & POD & FAR & CSI \\
\hline 0.505 & 0.039 & 0.495 & 0.978 & 0.833 & 0.166 \\
\hline
\end{tabular}

Table 2 - Skill scores evaluations

Results are reported in Table 2 In the Radar-Gauge column, POD and CSI values show a quite good agreement between radar and rain gauges, while a very low FAR means an improbable detection of rainfall when it does not occur (radar is not the truth, but it is still a good observer!). From the Radar-WRF column, we can deduce that a forecast failure is very low, since POD is very close to 1 . This means that when rain is detected by radar, WRF forecasts it. On the contrary, looking at FAR index, when WRF model forecasts rain, radar often doesn't observe it. This could be due to a couple of factors: probable presence of partial beam occultation phenomena over rain gauges position due to orography (strong radar underestimation), not perfect synchronization between forecast and observations: rainfall event forecast by WRF seems to be longer than the observed one by radar. CSI confirms it, as its low value represents that false alarms seem to be much greater than successes (failures are lower than successes, as POD demonstrates).

\section{CONCLUSIONS}

In conclusion, a good qualitative agreement is clearly evident, in particular for what concerns the feasibility to adopt TITAN software for identification, tracking and forecast of high space-time resolution precipitation fields observed by short-range, X-band Micro Radars. As far as the evaluation of Radar observations, WRF forecasts and rain gauge data quantitative agreement is concerned, some differences may occur. Margins for improvements are clearly possible: a radar data bulk adjustment on the basis of rain gauge could be applied and a more thorough research of different WRF physics options schemes could improve WRF rainfall forecast.

\section{References}

[1] M. Dixon, and G. Wiener, "TITAN - A Radarbased Methodology", J. of Atmosph. and Oceanic Tech., 10(6), 785-797, 1993.

[2] D. S. Wilks, "Statistical methods in Atmospheric Sciences. An introduction", Academic Press, pp 467, 1995. 